\title{
Optimization of Cylindrical Grinding Process Parameters of OHNS Steel (AISI 0-1) Rounds Using Design of Experiments Concept
}

\author{
M.Melwin Jagadeesh Sridhar ${ }^{1}$ M.Manickam ${ }^{2}$ V.Kalaiyarasan ${ }^{3}$ \\ M.Abdul Ghani Khan ${ }^{4}$ and Ttm.Kannan ${ }^{5}$ \\ ${ }^{1}$ PG Scholar, ${ }^{2}$ Asst.professor, ${ }^{3}$ Asst.professor, ${ }^{4}$ Professor. ${ }^{5}$ Asst.Professor, \\ ${ }^{1,2,3,4}$ Department of mechanical Engineering, Ponnaiyah ramajayam college of engineering and Technology,Thanjavur-613 \\ 403,India.
}

${ }^{5}$ Department of mechanical Engineering, PRIST UNIVERSITY, Thanjavur-613 403, India.

\begin{abstract}
OHNS steel is a widely preferred material for manufacturing of Die blocks, fasteners, automotive components and cutting tools. Metal removal rate is an important performance factor to be considered in grinding process. Research activities that include experimental work and statistical analysis help in improving quality standards of manufacturing of components. Surface quality of OHNS steel after cylindrical grinding process is proposed to be studied in this experimental work using L9 orthogonal array selected for three levels and three input parameters. The inputs parameters are considered in this Experimental study are work speed, depth of cut and number of passes and response parameter is metal removal rate (MRR) during cylindrical grinding process. Higher metal removal rate is the main objectives of this machining process. The different machining parameters of OHNS steel of cylindrical grinding process are optimized by Signal to noise ratio and analyzed by Analysis of variance (ANOVA's).
\end{abstract}

Keywords: OHNS steel, Grinding parameters, MRR, $\mathrm{S} / \mathrm{N}$ ratio, Optimization.

\section{I-INTRODUCTION}

Grinding is the most widely used abrasive finishing process among all traditional processes used in production. In grinding operation the material is removed from the work piece surface by relative motion of a cylindrical wheel having abrasive particles embedded on its periphery. The abrasive particles are bonded together to form porous body which come into contact with work piece resulting in material removal. The size and distribution of grits along and wheel abrasive structure play an important role in grinding performance. The application of grinding is mainly available for simple geometries like cylindrical or plane surface where size is limited by grinding wheel movement. Also the metal removal rate can be maximized in very few grinding passes on work piece. The knowledge is mainly in the form of physical and empirical models which describe various aspects of grinding process. The present paper takes the following input process parameters namely work speed, depth of cut and number of passes. The main objective of this paper is to show the knowledge of grinding process can be utilized to predict the grinding performance and achieve optimal operating process parameters of various materials. Comley et al [1] concludes that, high efficiency of grinding operations with its high material removal rate helps to improve manufacturing cycle time while achieving surface integrity and finish requirements of alloy steel. M. N. Dhavlikar et al [2] conducted experiments on grinding of high hardened steel with various process parameters using design of experiments concept and finally conclude metal removal rate is based on feed rate of centre less grinding operations. M.Janardhan et al [3] explain that in cylindrical grinding metal removal rate and surface finish are important responses through various process parameters while grinding of En8 Steel material. It was found that the feed rate play an important role on metal removal rate of grinding process. A.J.Shih et al [4] conclude that higher speeds of grinding wheel reduce the chip thickness and results in higher metal removal rate in steel or ceramic materials. M.Janardhan et al [5] conducted experiment by using Taguchi methodology and predicted higher metal removal rate while grinding of En24 steel by surface response methodology, He conclude higher metal removal rate produced by medium level of feed rate. Jae -Seob Kwak et al [6] The analysis of cylindrical grinding process parameters of hardened SCM440 steel using response surface method. He also concludes structure of grinding wheel affect metal removal rate and decrease surface roughness. N.Alagumurthi et al [7] conduct that in optimization of cylindrical grinding process parameters on various steels such as AISI3310,AISI6150 and AISI52100 
using $\mathrm{Al}_{2} \mathrm{O}_{3}$ grinding wheel, It was found that depth of cut dominate all response parameters like metal removal rate, surface roughness, heat flow and tool wear(surface integrity).Choi, T.J et al [8] conducted experiments on cylindrical plunge grinding process on various ferrous materials and produced generalized practical models, he found that surface integrity depends upon the higher speed of grinding wheels. P.Krajnik et al [9] explains design of grinding factors such as wheel speed, work speed, feed rate and depth of cut with using design of experiments orthogonal array model and predicted the surface integrity of grinding parameters. L.P.Khoo et al [10] using genetic algorithm with response surface methodology optimization technique of steel on cylindrical grinding process parameters and concludes metal removal rate depends upon feed rate.

\section{Oil Hardening Non Shrinking Die Steel (OHNS)}

OHNS steel refers to a variety of carbon and alloy steels that are particularly well-suited to be made into tools such as Blanking and stamping dies, Punches, Rotary shear blades, Thread cutting tools, Milling cutters, Reamers, Measuring tools, Gauging tools, Wood working tools, Broaches and Chisels. The specific properties of OHNS steels are hardness, resistance to abrasion, ability to hold a cutting edge, and resistance to deformation at elevated temperatures.

Table 1 Chemical composition of OHNS steel

\begin{tabular}{|c|c|c|c|c|}
\hline $\mathrm{C}$ & $\mathrm{Mn}$ & $\mathrm{Cr}$ & $\mathrm{W}$ & $\mathrm{V}$ \\
\hline 0.95 & 1.15 & 0.5 & 0.5 & 0.2 \\
\hline
\end{tabular}

Table 2 Mechanical properties of OHNS Steel

\begin{tabular}{|c|l|l|l|l|}
\hline Maximum & $\begin{array}{l}\text { Yield } \\
\text { stress } \\
\begin{array}{l}\text { Stress } \\
\left(\mathrm{N} / \mathrm{mm}^{2}\right)\end{array}\end{array}$ & $\begin{array}{l}\text { Elongat } \\
\text { ion }\end{array}$ & $\begin{array}{l}\text { Impact } \\
\text { strength } \\
\left(\mathrm{N} / \mathrm{mm}^{2}\right)\end{array}$ & $\begin{array}{l}\text { Hardness } \\
\text { value }\end{array}$ \\
\hline 950 & 465 & $10 \%$ & 25 & 288 \\
\hline
\end{tabular}

Statement of Problem

The identification of cylindrical grinding problem for OHNS Steel rounds which cannot be tackled using conventional technique because of following problems occurs in cylindrical grinding process.

- High surface roughness.

- Difficult to achieve Close tolerance

- Poor Chip Breaking.

- Need more cutting pressure for machining.

- Need high hardness grinding wheel for machining.

\section{II-EXPERIMENTAL SETUP}

The goal of experimental work was to investigate the effect grinding parameters with the process parameters of wheel speed, Number of pass and Depth of cut influencing the metal removal rate of OHNS Die steel. The work material OHNS Die steel in the form of round with $25 \mathrm{~mm}$ diameter and length $70 \mathrm{~mm}$. There are 9 experiments are conducted with different machining parameters for determine optimal solution of cylindrical grinding process.

Levels

Factors

Response Parameters - Metal removal Rate

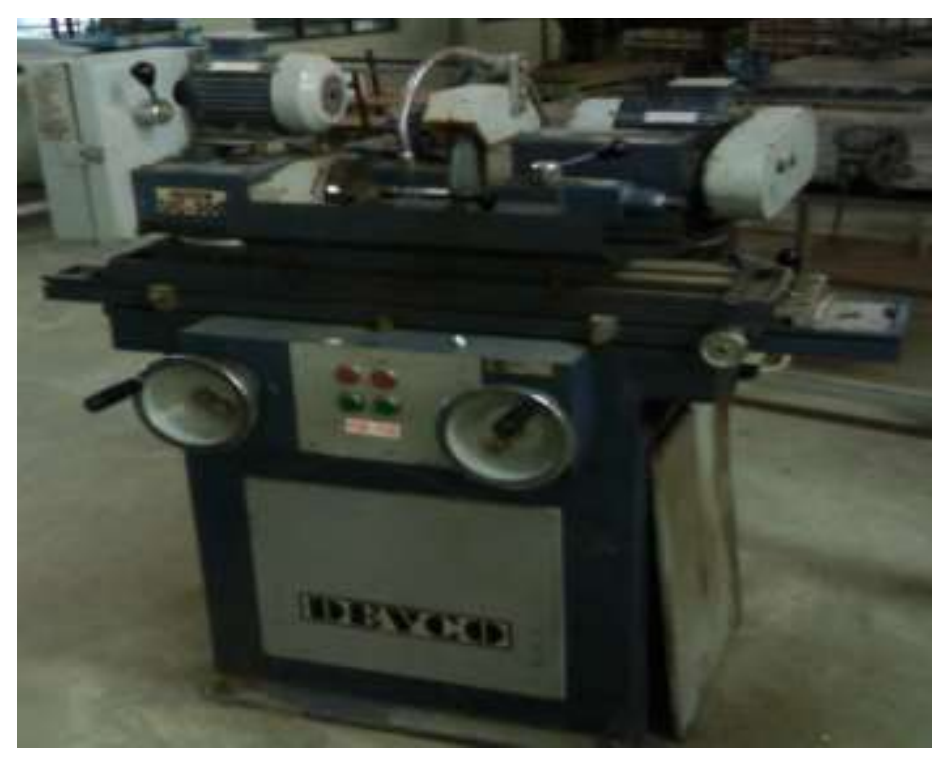

Fig 1. Cylindrical grinding Machine

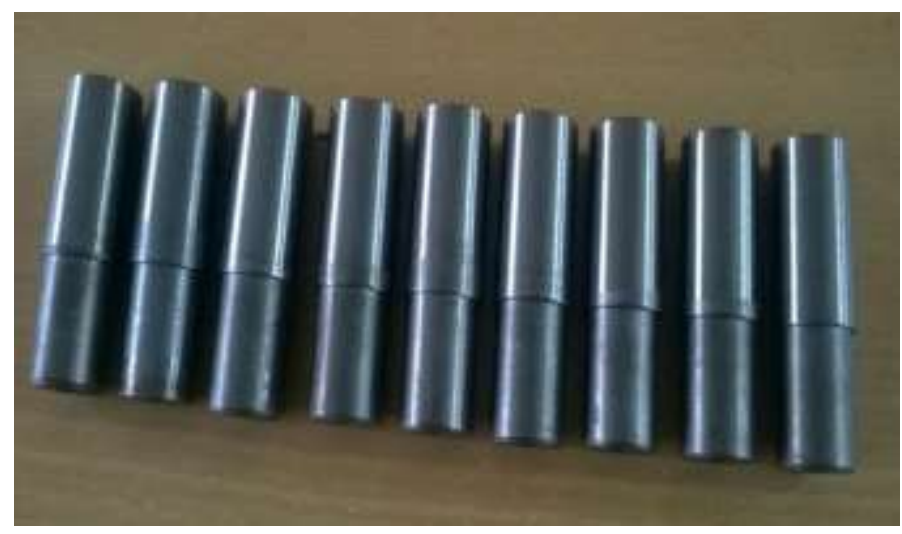

Fig 2 OHNS steel rounds 
International Journal of Engineering Trends and Technology (IJETT) - Volume 17 Number 3 - Nov 2014

Methodology

$>$ State the problem

$>$ State the objectives of experiments

$>$ Select the factors that may influence the selected quality characteristics

$>$ Identify quality and noise factors

$>$ Select levels for the factors

$>$ Select appropriate orthogonal array

$>$ Select interactions that may influence the selected quality characteristics

$>$ Conduct the tests described by trails in orthogonal array

$>$ Analyze and interpret results of the experimental trails

$>$ Conduct confirmation experiment

Taguchi Design of Experiments

Taguchi method is a powerful tool in quality Optimization makes use of a special design of orthogonal array (OA) to examine. Number of experiments used to design the orthogonal array for 3 parameters and 3 levels of grinding parameters.

$$
\begin{aligned}
\text { Minimum experiments } & =[(\mathrm{L}-1) \mathrm{X} \mathrm{p}]+1 \\
& =[(3-1) \mathrm{X} 3]+1=7 \\
& \approx \mathrm{L} 9
\end{aligned}
$$

Based on the Design of Experiments concept $\mathrm{L}_{9}$ Orthogonal Array (OA) is selected for cylindrical grinding parameters of OHNS steel rounds.

Table 3.Taguchi's L 9 Orthogonal Array

\begin{tabular}{|c|c|c|c|}
\hline Test No. & $\begin{array}{c}\text { Work } \\
\text { speed } \\
(\mathrm{rpm})\end{array}$ & $\begin{array}{c}\text { Depth of } \\
\text { cut(mm) }\end{array}$ & No of pass \\
\hline 1 & 1 & 1 & 1 \\
\hline 2 & 1 & 2 & 2 \\
\hline 3 & 1 & 3 & 3 \\
\hline 4 & 2 & 1 & 2 \\
\hline
\end{tabular}

\begin{tabular}{|c|c|c|c|}
\hline 5 & 2 & 2 & 3 \\
\hline 6 & 2 & 3 & 1 \\
\hline 7 & 3 & 1 & 3 \\
\hline 8 & 3 & 2 & 1 \\
\hline 9 & 3 & 3 & 2 \\
\hline
\end{tabular}

Table4 Cylindrical grinding parameters

\begin{tabular}{|c|c|c|c|}
\hline Test No. & $\begin{array}{c}\text { work speed } \\
\text { (rpm) }\end{array}$ & $\begin{array}{c}\text { Depth of } \\
\text { cut(mm) }\end{array}$ & No of pass \\
\hline 1 & 150 & 0.02 & 1 \\
\hline 2 & 150 & 0.04 & 2 \\
\hline 3 & 150 & 0.06 & 3 \\
\hline 4 & 250 & 0.02 & 2 \\
\hline 5 & 250 & 0.04 & 3 \\
\hline 6 & 250 & 0.06 & 1 \\
\hline 7 & 350 & 0.02 & 3 \\
\hline 8 & 350 & 0.04 & 1 \\
\hline 9 & 350 & 0.06 & 2 \\
\hline
\end{tabular}

\section{III-RESULT AND DISCUSSION}

After conducting the experiment of cylindrical grinding on OHNS Steel cylindrical rounds the following results were obtained.

1. Number of pass is a dominating parameter of metal removal rate (MRR) of cylindrical grinding process of OHNS steel rounds.

2. The optimum parameter for Metal removal rate of cylindrical grinding process of OHNS steel cylindrical rounds were $150 \mathrm{rpm}$ of workspeed, $0.02 \mathrm{~mm}$ of depth of cut and 1 number of pass from conducted experiments. 
International Journal of Engineering Trends and Technology (IJETT) - Volume 17 Number 3 - Nov 2014

3. It was found that the material removal rate (MRR) of OHNS steel rounds greatly depends upon the number of passes on cylindrical grinding process.

4. OHNS steel provides good machinabilty characteristics and Produce excellent surface finish.

5. The work speed, Depth of cut and Number of passes are dependable parameters of larger metal removal rate of cylindrical grinding process on OHNS steel rounds.

6. Cylindrical grinding is an essential process for final machining of OHNS steel rounds provides smooth surface and precise tolerance.

\begin{tabular}{|c|c|c|c|}
\hline Delta & 2.22 & 0.85 & 6.85 \\
\hline Rank & 2 & 3 & 1 \\
\hline
\end{tabular}

The table 6 represent the Number of pass is a influencing parameter (Rank 1)of material removal rate (MRR) of OHNS steel rounds while cylindrical grinding process calculated from signal to noise ratio.

Table 5 Cylindrical Grinding parameters of metal removal rate

\begin{tabular}{|c|c|c|c|c|}
\hline $\begin{array}{c}\text { Test } \\
\text { No. }\end{array}$ & $\begin{array}{c}\text { work } \\
\text { speed } \\
\text { (rpm) }\end{array}$ & $\begin{array}{c}\text { Depth of } \\
\text { cut(mm) }\end{array}$ & $\begin{array}{c}\text { No of } \\
\text { pass }\end{array}$ & $\begin{array}{c}\text { MRR } \\
(\text { Gms/Sec) }\end{array}$ \\
\hline 1 & 150 & 0.02 & 1 & 0.061789 \\
\hline 2 & 150 & 0.04 & 2 & 0.032556 \\
\hline 3 & 150 & 0.06 & 3 & 0.027382 \\
\hline 4 & 250 & 0.02 & 2 & 0.020556 \\
\hline 5 & 250 & 0.04 & 3 & 0.0152 \\
\hline 6 & 250 & 0.06 & 1 & 0.031579 \\
\hline 7 & 350 & 0.02 & 3 & 0.021382 \\
\hline 8 & 350 & 0.04 & 1 & 0.058105 \\
\hline 9 & 350 & 0.06 & 2 & 0.052389 \\
\hline
\end{tabular}

Table 6 Response Table for Signal to Noise Ratios (Larger is better)

The table 7 shows ANOVA values of cylindrical grinding process and bigger value of F-test represents Number of pass is a dominating parameter while achieving larger metal rate.

\section{The F-test}

\begin{tabular}{|c|c|c|c|}
\hline Level & $\begin{array}{c}\text { Work } \\
\text { speed }\end{array}$ & Depth of cut & No of pass \\
\hline 1 & -23.31 & -23.59 & -20.88 \\
\hline 2 & -25.44 & -24.44 & -23.35 \\
\hline 3 & -23.22 & -23.94 & -27.73 \\
\hline
\end{tabular}

The F-test is used for comparisons of the components of the total deviation. For example, in one-way or single-factor ANOVA, statistical significance is tested for by comparing the F test statistic

$$
F=\frac{\text { variance between treatments }}{\text { variance within treatments }}
$$


Table 7 ANOVA values of Cylindrical grinding parameters

\begin{tabular}{|c|c|c|c|c|c|c|}
\hline Source & $\begin{array}{l}\mathrm{D} \\
\mathrm{F}\end{array}$ & Seq SS & Adj SS & Adj MS & $\mathrm{F}$ & $\mathrm{P}$ \\
\hline $\begin{array}{l}\text { Work } \\
\text { speed }\end{array}$ & 2 & 0.0005254 & 0.0005254 & 0.0002627 & 2.36 & 0.297 \\
\hline $\begin{array}{l}\text { No of } \\
\text { pass }\end{array}$ & 2 & 0.0000529 & 0.0000529 & 0.0000265 & 0.24 & 0.808 \\
\hline DOC & 2 & 0.003763 & 0.003763 & 0.0018815 & 16.92 & 0.056 \\
\hline Error & 2 & 0.0002225 & 0.0002225 & 0.0001112 & -- & --- \\
\hline Total & 8 & 0.0045638 & ---- & --- & ---- & --- \\
\hline
\end{tabular}

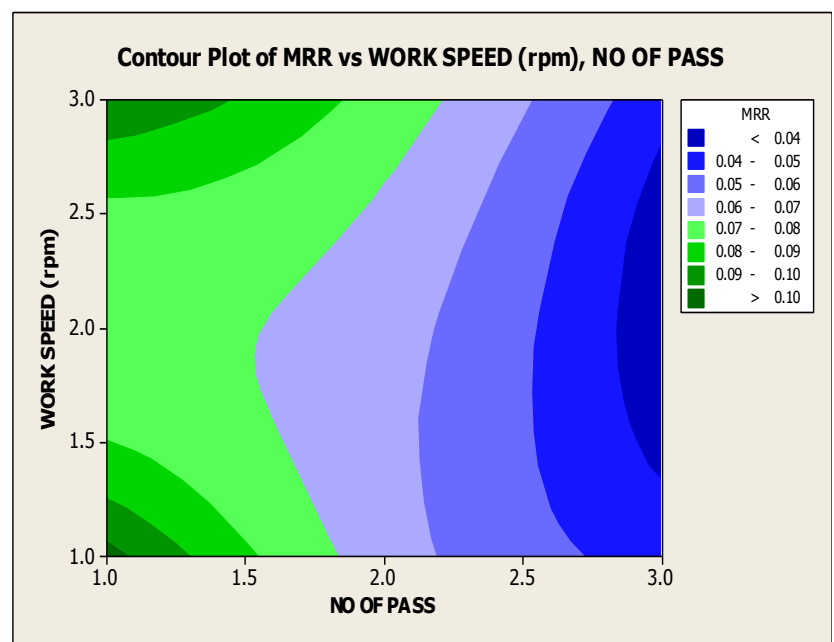

Fig 5 Contour plot for Metal removal rate of cylindrical grinding

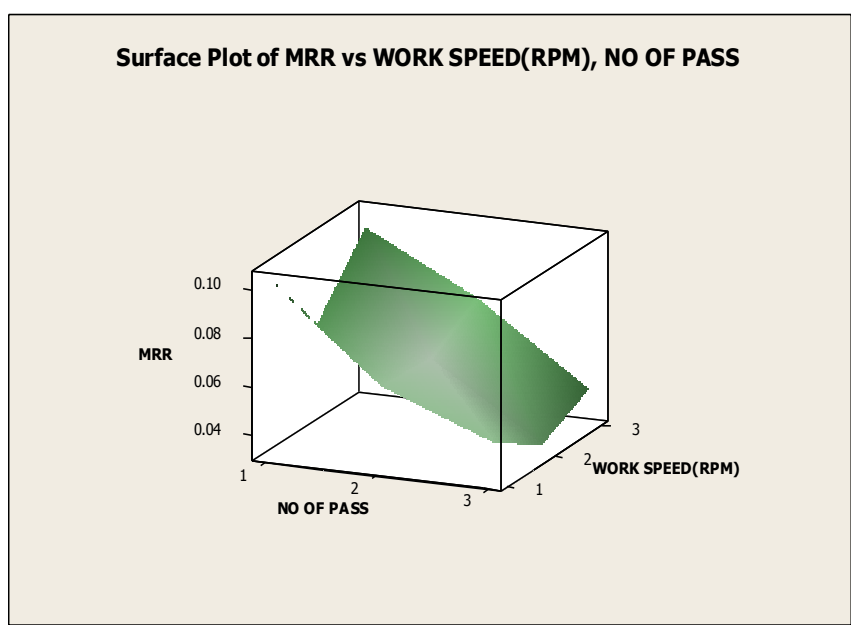

Fig 6 Surface plot for Metal removal rate of cylindrical grinding

The figure 5 and 6 denotes the graphical representation of optimal parameters of Metal removal rate during cylindrical grinding process. It is also mentioned that metal removal rate is increased by number of pass in cylindrical grinding process parameters.

\section{IV-CONCLUSION}

After conducting experiments on cylindrical grinding process, it conclude the following

- OHNS steel produces good surface finish during cylindrical grinding process with optimum grinding parameters.

- Precise tolerance can be achieved on OHNS steel rounds during cylindrical grinding. 
- Number of pass of grinding process play an important role for achieving larger metal removal rate in cylindrical grinding process

- The optimal parameter of OHNS steel rounds in cylindrical grinding process are $150 \mathrm{rpm}$ of wheel speed , $0.02 \mathrm{~mm}$ of depth of cut and 1 number of pass.

\section{ACKNOWLEDGMENT}

We express sincere thanks to our respected chairman Prof.P.Murugesan, Principal, Head of the Department of Mechanical Engineering of Ponnaiyah Ramajayam college of engineering and Technology, Thanjavur for given valuable suggestions and Motivate of this Effort.

\section{REFERENCES}

[1] P. Comley, I. Walton2, T. Jin, D.J. Stephenson, “A High Material Removal Rate Grinding Process for the Production of Automotive Crankshafts", Annals of the CIRP Vol.55/1/2006

[2] M. N. Dhavlikar, M. S. Kulkarni and V. Mariappan, Combined Taguchi and dual response method for optimization of a centerless grinding operation Journal of Materials Processing Technology, Volume 132, Issues 1- 3, 10 January 2003, Pages 90-94

[3] M.Janardhan, A.Gopala Krishna, "Determination and optimization of cylindrical grinding process parameters using taguchi method and regression analysis", ISSN 0975-5462, volume 3, page 5659-5665.

[4] A.J.Shih, M.B.Grant, T.M.Yunushonis, T.O.Morris, S.B.McSpadden, "Vitreous bond CBN wheel for high speed grinding of Zirconia and M2 Tool Steel", Transactions of NAMRI/SME, Vol. 26.

[5] Jae-Seob Kwak, Application of Taguchi and response surface methodologies for geometric error in surface grinding process, International Journal of Machine Tools and Manufacture, Volume45,Issue3, March2005, Pages327-334

[6] Jae -Seob Kwak, An analysis of grinding power and surface roughness in external cylindrical grinding of hardened SCM 440 Steel using the response surface method., international journal of machine tools \&manufacture 46 (2006) 304-312.

[7] N.Alagumurthi, K. Palaniraja and V.Soundararajan, cylindrical grinding a review on surface integrity. International journal of precision engineering and manufacturing vol. no 3.

[8] Choi, T.J., Subrahmanya, N., Li, H. and Shin, Y.C., 2008, "Generalized practical models of cylindrical plunge grinding process", International Journal of Machine Tools and Manufacture, 48:61-72.

[9] P.Krajnik, J.Kopac, A.Sluga, Design of grinding factors based on response surface methodology, journal of materials processing technology 162 (2005) 629-636.

[10] L.P.Khoo and C.H.Chen, Integration of response surface methodology with genetic algorithm, international journal of advanced manufacturing technology 18(2001) 483-489. 